УДК 141.7

$10.17213 / 2075-2067-2020-5-265-274$

\title{
СОЦИАЛЬНО-ФИЛОСОФСКИЕ АСПЕКТЫ ИДЕНТИФИКАЦИИ И КЛАССИФИКАЦИИ НАЦИОНАЛИЗМА
}

\author{
(C) 2020 г. C. C. Черных
}

\section{Южнно-Российский государственный политехнический университет (НПИ) имени М. И. Платова, г. Новочеркасск, Россия}

Цель исследования заключается в экспликаџии различных способов идентификаџии и классификации начионализма, понимаемого в качестве серии мобилизационных прочессов, в результате которых та или иная начия приобретает способность демонстрировать собственную «избыточность» и эксиессивность.

Методологическую базу исследования представляют работы ведущих исследователей национализма, которые осмысливали данный феномен сквозь призму модернизации и эгалитаризачии наиболее развитых в экономическом и политическом плане европейских ообществ (К. Калхун, Л. Гринфельд); в контексте права наций на самоопределение (Р. Брубейкер, Б. Як); посредством противопоставления этнической культуры и гражданской воли (Г. Кон); сквозь призму политики «положительной деятельности» (Т. Мартин); в контексте «имунно-сферологической» дескрипџии наций как особых культурных систем (П. Слотердайк).

Результаты исследования. $B$ статье делается вывод о том, что интеллектуальный уровень изучения национализма в той или иной степени находится в зависимости от социально-философских дискурсов модернизма и перенниализма. В статье раскрывается эгалитарный контекст понимания национализма, возникщего в период революционных преобразований ряда ведущих капиталистических государств Западной Европьл. При этом обращается внимание на связь национализма с правом наций на самоопределение и вытекающими отсюда сепаратистскими тенденциями. В заключении отмечается необходимость синтеза методологических подходов понимания начионализма и его основных разновидностей, связанных с начиестрочтельством и современной государственной политикой.

Перспективу исследования составляет дальнейшая разработка методологических подходов идентификации и классификащии дискурсов о нащии и нациионализме.

Ключевые слова: национализм; наџия; государство; модернизм; перенниализм; сферология; эгалитаризм; сепаратизм; право нации на самоопределение; протонащионализм.

\section{SOCIO-PHILOSOPHICAL ASPECTS OF IDENTIFICATION AND CLASSIFICATION OF NATIONALISM}

\section{(C) 2020 S. S. Chernykh}

\section{Platov South Russian State Polytechnic University (NPI), Novocherkassk, Russia}

The purpose of the study is to explicate various ways of identifying and classifying nationalism, understood as a series of mobilization processes, as a result of which a particular nation acquires the ability to demonstrate its own «redundancy» and excess. 
The methodological basis of the study is represented by the works of leading researchers of nationalism, who primarily tried to comprehend this phenomenon: through the prism of modernization and egalitarianization of the most economically and politically developed European societies - K. Calhoun, L. Greenfeld; in the context of the right of nations to self-determinationR. Brubaker, B. Yack; by contrasting ethnic culture and civil will - H. Kohn; through the prism of the policy of "affirmative action» - T. Martin. The works of E. Smith demonstrated the difference between perennialism and modernism as between two theoretical paradigms of understanding nationalism. The studies of the modern philosopher P. Sloterdijk prompted us to the possibility of an «immune-spherological» description of nations as special cultural systems capable of supporting members of communities in ecstatic tension.

Results. The article concludes that the intellectual level of the study of nationalism, to one degree or another, depends on the socio-philosophical discourses of modernism and perennialism. The article reveals the egalitarian context of understanding nationalism that arose during the revolutionary transformations of a number of leading capitalist states of Western Europe. At the same time, attention is drawn to the connection between nationalism and the right of nations to self-determination and the separatist tendencies that follow from this. In the conclusion, the need to synthesize methodological approaches to understanding nationalism and its main varieties associated with nation-building and modern state policy is noted.

The prospect of the research is the further development of methodological approaches to the identification and classification of discourses about the nation and nationalism.

Key words: nationalism; nation; state; modernism; perennialism; spherology; egalitarianism; separatism; nation's right to self-determination; protonationalism.

Введение. Очевидно, что в основе нащионализма и его проявлений можно обнаружить дискурс о социально-политической, культурной и т.д. мобилизации индивидов под флагом «единой» нации, который, как правило, связан с идей самоопределения (нации) и коллективного выбора в пользу того или иного государственного устройства, а также неотчуждаемых правах граждан, собственно входящих в нацию. Поэтому с проявлениями национализма мы встречаемся именно в тех ситуациях, когда речь идет о мобилизации той или иной («воображаемой» или еще не признанной) нации и побуждением ее представителей к социальной активности, понимаемой в довольно широком смысле (от этнических волнений до культурной политики в сфере языка или антикоррупционных выступлений и актов массового гражданского неповиновения). Однако наибольшие «проблемы» с национализмом возникают в тех случаях, когда в дело вступают механизмы исключения, спровоцированные образом нации, в котором не предусмотрено места для целого ряда групп населения, подвергающихся яв- ной или даже скрытой дискриминации. При этом различные формы национализма могут быть вполне институциализированы и действовать в систематическом и перманентном режиме на уровне повседневных интеракций и восприятия социальной реальности. Вместе с тем национализм зачастую представляет собой процесс, в котором нация способна демонстрировать свою «избыточность», то есть может при определенных обстоятельствах порождать эксцессы, связанные с проявлением насилия (причем не только физического, но и символического).

Методологические подходы классификации национализма и его основных направлений. Интересно отметить, что сам концепт «нация» начинает использоваться в Новое время как маркер определенной гражданской активности, то есть обозначает процесс, в котором «масса» (как правило, подданных) превращается в субъект (причем зачастую именно в субъект революционных изменений). В данной связи Ж. Делез и Ф. Гваттари справедливо отмечали, что 
«нация - это сама операция коллективной субъективации, коей соответствует современное Государство как процесс подчинения. Именно в этой форме Государства-нации со всеми его возможными разнообразиями Государство становится моделью реализации для капиталистической аксиоматики. Это вовсе не значит, что нации суть явления или идеологические феномены, но напротив, они - страстные и живые формы, где впервые реализуются качественная однородность и количественная конкуренция абстрактного капитала» [5, с. 776]. Таким образом, современные нации можно вполне сравнить по аналогии с экономическими корпорациями («умными» телами), которые, однако в отличие от последних, отличаются меньшей рациональностью и несравненно большей склонностью к массовой аффектации. Если корпорации преследуют, прежде всего, экономические интересы, то нации стремятся к порождению коллективных аффектов идеологического характера, которые зачастую очень отдаленно связаны с реальными экономическими интересами основной массы населения, вовлеченного в поле национального воздействия.

Таким образом, нация включает в себя представителей различных классов, конфессий или даже этнических групп, людей, объединенных общими историческими обстоятельствами, но при этом усвоивших специфические способы совместного сосуществования в едином «организме». При этом сама нация продолжает восприниматься как символическая сфера, поддерживающая солидарность между людьми, причем обладающая, по сути дела, серьезным «иммунологическим» значением. Таким образом, воспользовавшись интуицией П. Слотердайка, можно представить нации как мыслимые (и одновременно воображаемые) сферы, которые помогают формировать общие структуры восприятия окружающей человека реальности и вырабатывать правила совместной жизни. «Поскольку обитание всегда означает формирование как малых, так и больших сфер, то люди - это существа, создающие круглые миры и окруженные определенными горизонтами. Жить в сферах означает создавать такое измерение, в которое могут быть включены люди. Сферы - это эффективные с точки зрения иммунных систем пространственные творения для экстатических существ, в которых действует внешнее» $[8$, с. 25]. Но обитание внутри определенной нации должно перманентным образом поддерживаться не всегда заметными и тем более осознаваемыми возбуждающими (преимущественно культурно-символическими) импульсами.

Вместе с тем наиболее радикальные и экстремальные формы национализма в его сферологическом и органическом понимании активизируются в те исторические моменты, когда в доминирующих группах населения значимым становится мнение о том, что нации как иммунологической сфере угрожают «враждебные», причем зачастую не только внешние, но и внутренние силы, которые способны подорвать и ослабить ее иммунитет изнутри путем заражения вредными социальными «болезнями». В этом случае «враги нации» или лица, подозреваемые в неполной лояльности по отношению к ее здоровой це-

Таблица 1

\section{Свойства нации с точки зрения перенниалистов и модернистов [9]}

\begin{tabular}{|c|c|}
\hline Перенниалисты & Модернисты \\
\hline \multicolumn{2}{|c|}{ Нация } \\
\hline $\begin{array}{l}\text { культурная общность } \\
\text { извечный феномен } \\
\text { уходит своими корнями в прошлое } \\
\text { органическая } \\
\text { целостная } \\
\text { качество } \\
\text { народная } \\
\text { основана на родовой принадлежности }\end{array}$ & $\begin{array}{l}\text { политическая общность } \\
\text { феномен нового времени } \\
\text { создана } \\
\text { механическая } \\
\text { разделенная } \\
\text { ресурс } \\
\text { создается элитой } \\
\text { основана на коммуникации }\end{array}$ \\
\hline
\end{tabular}


лостности, зачастую начинают подвергаться исключению, дискриминации или даже в наиболее крайних случаях физическому уничтожению, а сами националисты примеряют на себя роль якобы наиболее компетентных агентов, способных не только обнаруживать подобные вирусы, но и превентивно ликвидировать их в зародыше.

Обнаружение множества разнообразных национализмов ставит перед исследователями вопрос о необходимости их формальной классификации. В данной связи британский исследователь Э. Смит предложил довольно точную классификацию различных подходов интерпретации национализмов, которые можно разделить на две большие группы: перенниалистов и модернистов (табл. 1).

В процессе изучения конкретных националистических дискурсов оба предложенных Э. Смитом подхода могут вполне сочетаться, тем более, что сами националисты (лица, эксплуатирующие подобный дискурс) в большинстве случаев (в зависимости политической тактики или стратегии) варьируют собственное представление о нации, например, как в целом об этнической категории, но также не исключающей возможность полноценного включения в нее на гражданской (или другой надэтнической) основе и т.д.

Итак, в идеале перенниалисть понимают нацию в первую очередь как:

1) политизированное этническое сообщество;

2) культурно преемственную (этническую) общность, существующую с незапамятных времен;

3) общность, «неразрывно» связанную со своей исторической Родиной (родной, священной землей);

4) сообщество, в своей основе выражающее интересы простого народа (его «духа»);

5) субстанцию, обладающую определенными конкретно-всеобщими свойствами, которые также прослеживаются у ее представителей на протяжении длительного времени (например, «ментальность», «национальный характер» и т.д.);

6) внутреннее единство и целостность, часто постигаемые интуитивным образом;

7) залог ее (нации) дальнейшего успешного существования - связь с традициями и наследием предков.
Установки модернистов в понимании нации в сравнении с перенниалистами, согласно Э. Смиту, существенно отличаются в каждом из семи выше обозначенных пунктов. Так, модернисты полагают, что нация, представляет собой:

1) политическое объединение граждан, существующих на определенной территории (законный представитель нации - гражданин страны, безотносительно того, к какой этнической группе он принадлежит);

2) почти исключительно современное политическое явление, возникшее в эпоху модерна, которое тесно связано с развитием капитализма и формированием общества эгалитарного типа;

3) искусственное (сотворенное) образование, всегда выступающее как результат предшествующего государственного проекта;

4) «дело рук» элит, которые конструируют ее по собственному усмотрению;

5) концентрацию определенных технологических ресурсов, обеспечивающих способность к деятельности;

6) классово-разделенную общность, в которой составляющие ее группы обладают собственными потребностями и интересами;

7) принципы социальной солидарности, основанные на наличии общего гражданства.

Тема национализма в значительной степени связана с проблемами модернизации, возникновением и экспансией капитализма, империализма и колониализма на протяжении последних пяти веков. В нее также, как правило, включается анализ развития медиа и глобальных средств коммуникации. Но это вовсе не значит, что протонационалистические в той или иной степени дискурсы являются почти исключительно феноменами «современности», а, следовательно, не могут быть обнаружены в предшествующие исторические эпохи, например, в античности и древнем мире. «Несмотря на современность, - как в данной связи отмечал Г. Кон, - некоторые фундаментальные черты национализма были сформированы давно. Корни национализма берут свое начало в той же самой почве, что и западная цивилизация, от древних евреев и древних греков. У обоих народов было четко определенное сознание своего отличия от всех других народов: евреев от язычников, греков от варваров. Носителем группового 
сознания был для них не царь или священство, а народ в целом, каждый еврей или каждый грек. У других народов древности только правители с их империями оставили в истории свои следы. У евреев и греков это был национальный характер и духовная творческая энергия людей, которые выдержали испытание временем. Именно потому, что их культурная преемственность оказалась сильнее расовой, политической или географической преемственности, они живут сегодня. Идея национального государства была им неизвестна, но у них было сильное сознание культурной миссии» [2, с. 11]. Не случайно, что именно эти древние народы станут во многом эталонными для представителей современного национализма, неким живым подтверждением перенниалистической точки зрения на существование наций. Вместе с тем речь здесь все-таки идет об этнических сообществах, которые сначала лишились собственной государственности и смогли осуществить ее «пересборку» только в эпоху Нового времени, действительно ориентируясь на сохраненный и во многом эксклюзивный культурный капитал.

Вместе с тем можно предположить, что национализм в его современном значении во многом является результатом секуляризации, в результате которой конфессии, напрямую связанные с практиками мировых религий, существенно снизили свое влияние на многие социально-политические процессы, происходящие в среде собственной паствы. Очевидно, что, по крайней мере, в Европе националистические движения существенно блокировались, например, христианством, и в тот исторический период, когда именно конфессиональная идентичность превалировала над собственно этническим происхождением, не говоря уже про то, что многие этнические идентичности были сами отформатированы до современного состояния в результате длительной включенности в ту или иную конфессиональную страту.

Эгалитарный контекст понимания национализма в эпоху Нового времени. Рассматривая национализм в семантической ретроспективе, преимущественно в европейском контексте, необходимо обратить внимание, что процессу отождествления таких понятий, как «нация» и «народ» предшество- вали очень серьезные мировоззренческие изменения, то есть должен был сформироваться новый дискурс о нации. «В определенный исторический момент - а именно в Англии начала XVI в. - слово “нация" в его “соборном” значении “элита" было применено в отношении населения страны и стало синонимично слову “народ”. Эта семантическая трансформация означала возникновение первой в мире нации, нации в современном смысле этого слова - и возвестила начало эры национализма. Эта концептуальная революция имела колоссальнейшее значение, значение, которое подчеркивалось еще и тем фактом, что до своей национализации слово "народ" обозначало население определенного региона и именно низшие классы этого населения. Слово это наиболее часто использовалось в значении "чернь" или “плебс". Понятия "нация” и “народ” стали тождественны. Таким образом, народные массы сразу возвысились до положения элиты (сначала только политической)» [4, с. 11]. Конечно, нельзя полностью согласиться с вышеприведенным мнением Л. Гринфельд, что народные массы (пускай даже в Англии) сразу, как при коммунизме, приобрели реальный статус новой элиты, но тенденция к эгалитаризации общественного устройства в период революционного натиска схвачена верно.

В данной связи важно также вспомнить о различении, которое в отношении классификации национализмов предложил Г. Кон, полагавший, что, рассуждая об этом явлении, мы зачастую имеем дело с двумя типами национализма - волюнтаристским и органическим. Первый связан с политическим определением народа в период революции, то есть его адепты исходят из необходимости «рождения» самой нации, второй, напротив, проистекает из романтического и примордиалистского взгляда, что нация (как правило, совпадающая с этносом или союзом древних племен) существует с незапамятных времен и порой лишь только требует своего пробуждения. Вместе с тем Г. Кон усматривал в различении национализмов географический аспект [1], когда полагал, что волюнтаристский национализм исторически был характерен в первую очередь для западных обществ, а именно: Франции, Англии и США, тогда как разновидность органического национа- 
лизма в той или иной степени доминировала в Германии и странах Восточной Европы.

Национализм, явившийся на историческую арену из духа буржуазных революций, связанных с либерализацией западных обществ, имел важное историческое и, пожалуй, структурообразующее значение для формирования представлений об основных критериях и составляющих модернизации. В данной связи американская исследовательница Л. Гринфельд считает, что Англия является именно такой страной, в которой национализм (в его преимущественно волюнтаристской форме) впервые проявился в своей «современной» и довольно прогрессивной, эгалитарной форме легитимации политической власти на основе обращения к народному большинству и его политической воле. «В качестве синонима слова "нация" - то есть элита — слово "народ" утратило уничижительный оттенок и стало обозначать позитивное единство в самом высшем смысле. "Народ” стали видеть носителем верховной власти, основой политической солидарности и главнейшим объектом преданности. Такому переопределению ситуации должен был предшествовать колоссальный сдвиг в мировоззрении» [4, c. 11]. Здесь, однако, важно уточнить, что в целом речь в вышеприведенной цитате речь идет о постепенном и противоречивом «выходе» из классического феодального порядка господства, где определяющую роль играл пасторский тип власти, связанный напрямую с интернациональной ролью и влиянием Церкви, который существенно блокировал протонациональные тенденции, характерные, например, для родоплеменных обществ.

В периоды глобальных военных конфликтов националистические дискурсы стали наиболее востребованы в обществах, где агрессивные и захватнические действия правительств великих держав стали легитимироваться не отсылкой к воле царей и королей, а подаваться как желание (причем часто очень древнее) самой нации (увеличивать собственные территории и влияние по всему миру). Начиная с периода наполеоновских войн и вплоть до окончания второй мировой войны, национализм был инструментализирован в качестве важного средства армейской моби- лизации населения, по крайней мере, именно он в значительной степени обеспечивал символическое (идеологическое) сопровождение массовых военных компаний. С другой стороны, в терминах национализма происходило осмысление положения стран и народов в условиях зримых фактов экономической и политической глобализации. «Дискурс национализма возник отчасти вследствие стремления осмыслить идентичности в масштабе и форме, которые отвечали развитию современных капиталистических рынков и современных государств с их значительными административными возможностями и способностями мобилизации граждан для участия в войне» $[6$, c. 186]. Однако также не вызывает сомнений, что националистические дискурсы оказывались очень восприимчивыми к недовольству различных групп граждан своим нынешним (актуальным) положением, особенно в сравнении с упущенными возможностями или собственным (как правило воображаемым) «великим» прошлым.

Национализм во многом является следствием актуализации сразу множества наций и их последующим постоянным взаимодействием на международной арене именно в современном значении, то есть вне прежних рамок династических связей и систем престолонаследия. «Идея нации также по своей сути интернациональна и частично действует через противопоставление друг другу различных наций. Националистическая риторика предполагает способ концептуализации идентичности любой страны, который предполагает существование других более или менее сравнимых единиц» [6, с. 188]. В данной связи можно вполне согласиться с тем мнением, что национализм отчасти порождается конкуренцией различных наций или соперничеством между различными образами предполагаемой (конструируемой) нации в представлении политических противников. При этом националисты, как правило, исходят из того, что одни нации более или менее эффективны на международной политической арене, причем некоторые из них в большей степени способны формировать мировую культуру.

Вместе с тем представители отдельных этнических сообществ (этнофоры) могут в свою очередь претендовать на особый го- 
сударствообразующий статус в рамках единой нации, который, однако, далеко не во всех случаях сулит их общности привилегии, но напротив, может быть интерпретирован и инструментализирован также в терминах «позитивной» дискриминации представителей большинства [7]. Поэтому несовпадение национальных образов, а также крайне распространенное понимание нации сквозь призму этничности (особенно в РФ) приводит к тому, что мы постоянно обнаруживаем внутри крупных сообществ национализмы, стремящиеся вещать от имени «меньшинств», либо национализмы, которые желают обосновать и распространить собственный дискурс, обращаясь к проблемам «большинства». При этом как первые, так и вторые стремятся акцентировать внимание на том, что их этнические «подопечные» (меньшинства/большинства) в течение длительного времени (возможно, многих веков) подвергались угнетению или даже остаются угнетенными в настоящий момент.

Национализм и сепаратизм. Изучая тот или иной конкретный националистический дискурс, вне зависимости от того, какие компоненты - например, этнические или гражданские - в нем преобладают, справедливо идентифицировать его на предмет отношений и зависимости с актуальным государством и его территориальной целостностью. «С аналитической точки зрения, менее неопределенное различие, нежели различие между гражданской и этнической формами национализма, можно установить между государственно-фреймированным и контргосударственным пониманиями национальности и форм национализма. В первом “нация" мыслится конгруэнтной государству, его институциональному и территориальному фрейму. Во втором “нация” представляется отличной от территориального и национального фрейма существующего государства или государств и часто - противоположной ему» [3, с. 261-262]. Таким образом, можно обнаружить либо национализмы, стремящиеся к объединению различных территорий и даже укрупнению действующего государства на основе усвоения комплекса идей ирредентизма (от итальянского irredentismo, от terre irredente - неосвобожденные земли), или другой (противоположный) тип национализмов, в той или иной степени нацеленных на сецессию, отделение и сепаратизм от «враждебного» национального ядра.

Вместе с тем можно обнаружить исторически состоявшиеся типы наций (например, Австрия и Швейцария, в их отличии от Германии), в рамках которых культивировались соответствующие типы национализмов, где сама этничность не выступала драйвером форсирования отдельной государственности, но, напротив, могла бы при определенных условиях стать аргументом в пользу ирредентистских тенденций, направленных на объединение с этнически близкими («родственными») странами и территориями. «Контргосударственные национализмы. .., - как справедливо замечает Р. Брубейкер, - не обязательно являются специфически этническими; национальность, представляемая отличной от существующего государства или противоположной ему, не обязательно понимается в этнических или даже, шире, в этнокультурных терминах. Совершенно независимо от рассмотренного выше различия между узкими этническими и широкими этнокультурными пониманиями национальности контргосударственные определения нации могут основываться на территории, на исторических привилегиях провинций или на наличии отдельной политической истории раннего вхождения в более крупное государство» [3, c. 264]. В данной связи в качестве наиболее хрестоматийного исторического примера (способного наглядно продемонстрировать силу и мощь гражданского национализма) стоит вспомнить о сепаратистских устремлениях США и их последующем успешном отделении в результате войны за независимость от Великобритании в конце VXIII века.

При этом так называемый этнический или региональный национализм далеко не всегда имеет сильное распространение среди представителей тех народов, которые уже имеют «собственные» крупные государства, в том ключе, что их культура фундирует основные институты тех стран, где они занимают доминирующее (прежде всего в официальном и символическом смысле) положение (например, испанцы-кастильцы в Испании), тогда как в среде представителей этнических меньшинств и жителей автономных регионов 
националистические настроения, направленные на создание и международное признание собственной нации, по-прежнему пользуются определенной популярностью (например, каталонцы, баски в той же Испании). Причем в данном пункте, то есть в наиболее острые периоды национального самоопределения, когда речь заходит о сецессии, национализм довольно сильно сближается с требованиями, характерными для политического либерализма. «Отстаивание всеобщего права на национальное самоопределение, - как считает Б. Як, - это наиболее провокативный вклад либерализма в националистическую политику» [10, с. 387]. К тому же, несмотря на свое происхождение, из гражданского контекста данное право (народа на самоопределение) зачастую открывает дорогу этническому национализму, в рамках которого может довольно легко происходить легитимизация сепаратизма.

В конфликтных ситуациях и в периоды, когда центральная власть оказывается относительно слабой, восставший народ наделяется легитимным правом создания собственного государства. В данной связи Б. Як полагает, что «право на национальное самоопределение (в его обыденном понимании) состоит из двух отдельных прав: права образовывать или формировать политическую организацию и права контролировать некую часть земной поверхности» [10, с. 391]. Национализм, таким образом, может быть понят как форма политической мобилизации в переходный период создания нового государственного образования, то есть в момент «самоопределения народа», который еще полностью не достиг поставленных целей, но уже в значительной степени актуализировал собственный сепаратистские ресурсы. При этом националистическая мобилизация может идти на спад вместе с буйными национальными чувствами, когда цели сецессии уже достигнуты, и новое государство в той или иной степени переходит в мирное русло своего дальнейшего строительства (когда люди менышее внимание обращают на символы, а в большей степени обеспокоены экономическими проблемами).

Заключение. В заключении представленной статьи необходимо сделать вывод о том, что, несмотря на разнообразие типов национализма и связанных с ним дискурсов, важно выделить несколько смысловых линий, по которым может происходить различение и описание его специфических форм в рамках социально-философских дисциплин. Прежде всего, вышеотмеченные различия касаются таких ведущих подходов в интерпретации национализма, как модернизм и перенниализм, причем в рамках первого подхода сама нация (не обязательно этнос) понимается как политический конструкт, возникший почти исключительно в современную эпоху, тогда как сторонники второго подхода полагают, что нации в той или иной степени существовали в предшествующие исторические эпохи, где также можно было обнаружить аналоги современного национализма. При этом очевидно, что исследователи, в той или иной степени находящиеся под влиянием перенниалистского дискурса, акцентируют внимание именно на этнических корнях даже вполне гражданских наций, существующих и в настоящее время. Вместе с тем в контексте изучения буржуазных революций Нового времени, происходивших преимущественно в Западной Европе, что в свою очередь связано с тем, что именно в этой части света был впервые достигнут резкий скачок производительных сил (подкрепленный научными достижениями) и возникли современные формы организации рациональной экономической деятельности (капиталистические корпорации), национализм стал пониматься как прогрессивный процесс, который запустил механизм эгалитаризации и демократизации (в широком смысле) современных обществ. Таким образом, национализм как форма солидаризации общества вне зависимости от классового деления может стимулировать те или иные сепаратистские тенденции сил, заинтересованных в сецессии, но при этом исходящих в своих действиях из вполне легитимного в мировой практике правового принципа, выражающего «право нации на самоопределение». Согласно также сферологической теории П. Слотердайка можно мыслить сами нации как «иммунологические» (культурно-политические) сферы, поддерживающие чувства солидарности и безопасности в сообществах, а национализм понимать как социальную активность, зачастую сопро- 
вождающуюся экстатическим возбуждением, возникающую в контексте угроз (часто воображаемых и мнимых) национальному единству или в периоды формирования новых сферических (объемлющих) образований.

\section{Литература}

1. Kohn H. The Idea of Nationalism: A Study in Its Origins and Background. - New York: The Macmillan Company, 1944. — 736 p.

2. Kohn H. Nationalism, its meaning and history. - Princeton, NJ: D. Van Nostrand Company, Inc., 1965. - $192 \mathrm{p}$.

3. Брубейкер Р. Этничность без групП. М.: Изд. Дом Высшей школы экономики, 2012. - $408 \mathrm{c}$.

4. Гринфельд Л. Национализм. Пять путей к современности. — М.: ПЕР СЭ, 2012.— $528 \mathrm{c}$.

5. Делез Ж., Гваттари Ф. Тысяча плато: Капитализм и шизофрения. - Екатеринбург: У-Фактория; М.: Астрель, 2010. — 895 с.

6. Калхун К. Национализм. - М.: Издательский дом «Территория будущего», 2006. - 288 c.

7. Мартин T. Империя «положительной деятельности». Нации и национализм в СССР, 1923-1939. - М.: Российская политическая энциклопедия (РОССПЭН): Фонд «Президентский центр Б.Н. Ельцина», 2011. - 855 c.

8. Слотердайк П. Сферы. Микросферология. - Т. І: Пузыри. - СПб.: Наука, 2005. - $649 \mathrm{c}$.

9. Смит Э. Д. Национализм и модернизм: Критический обзор современных наций и национализмов. - М.: Праксис, 2004. - 464 с.

10. Як Б. Национализм и моральная психология сообщества. - М.: Изд-во Института Гайдара, 2017. — 520 с.

\section{References}

1. Kohn H. The Idea of Nationalism: A Study in Its Origins and Background. - New York: The Macmillan Company, 1944. - 736 p.

2. Kohn H. Nationalism, its meaning and history. - Princeton, NJ: D. Van Nostrand Company, Inc., 1965. - $192 \mathrm{p}$.

3. Brubejker R. Jetnichnost' bez grupp [Ethnicity without groups]. - Moscow: Izd. Dom Vysshej shkoly jekonomiki, 2012. — 408 p.

4. Grinfel'd L. Nacionalizm. Pjat' putej k sovremennosti [Nationalism. Five paths to modernity]. - Moscow: PER SJe, 2012. - 528 p.

5. Delez Zh., Gvattari F. Tysjacha plato: Kapitalizm i shizofrenija [Thousand plateaus: Capitalism and schizophrenia]. - Ekaterinburg: U-Faktorija; Moscow: Astrel', 2010. — 895 p.

6. Kalhun K. Nacionalizm [Nationalism]. Moscow: Izdatel'skij dom «Territorija budushhego», 2006. - $288 \mathrm{p}$.

7. Martin T. Imperija «polozhitel'noj dejatel'nosti». Nacii i nacionalizm v SSSR, 19231939 [The Empire of «positive activity». Nations and nationalism in the USSR, 1923-1939]. Moscow: Rossijskaja politicheskaja jenciklopedija (ROSSPJeN): Fond «Prezidentskij centr B. N. El'cina», 2011. - 855 p.

8. Sloterdajk P. Sfery. Mikrosferologija [Spheres. Microspherology]. - Vol. I: Puzyri [Bubbles]. — Saint-Petersburg: Nauka, 2005. — 649 p.

9. Smit Je. D. Nacionalizm i modernizm: Kriticheskij obzor sovremennyh nacij i nacionalizmov [Nationalism and modernism: a Critical review of modern Nations and nationalisms]. Moscow: Praksis, 2004. - 464 p.

10. Jak B. Nacionalizm i moral'naja psihologija soobshhestva [Nationalism and moral psychology of the community]. - Moscow: Izd-vo Instituta Gajdara, 2017. — 520 p. 


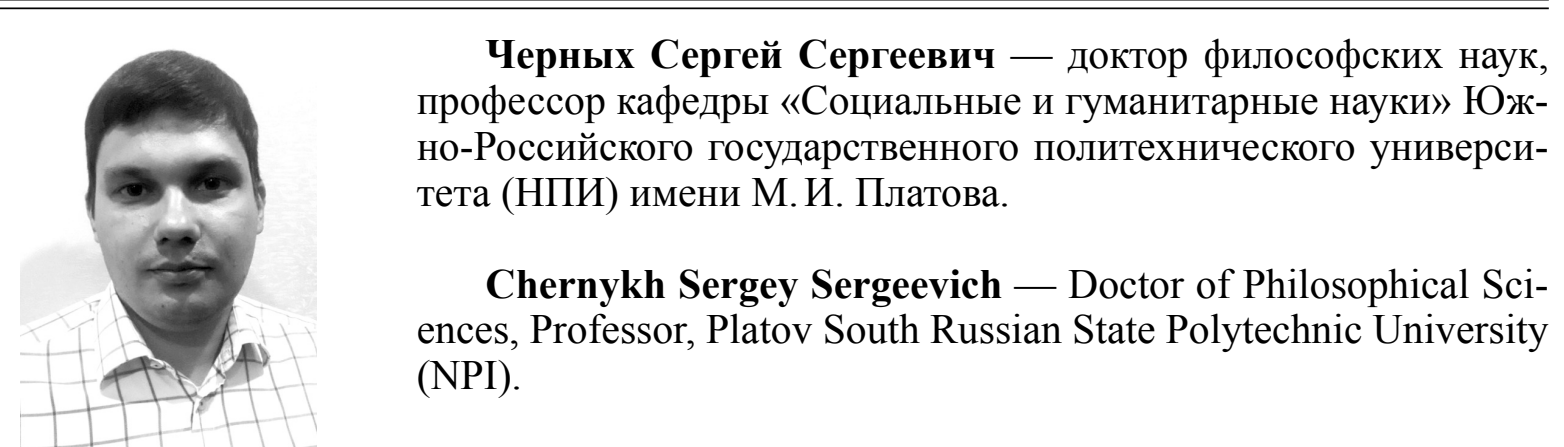

346428, г. Новочеркасск, ул. Просвещения, 132

132 Prosveshcheniya st., 346528, Novocherkassk, Russia

E-mail: s.s.chernykh@mail.ru 